\title{
RANCANG BANGUN SISTEM INFORMASI PEMBELAJARAN ANATOMI TUBUH MANUSIA BERBASIS ANDROID (STUDI KASUS: SDN CIHUNI 1)
}

\author{
No fitri Heriyani ${ }^{1}$ \\ 1) Universitas Muhammadiyah Tangerang / Fakultas Teknik, \\ Program Studi Informatika \\ JI. Perintis Kemerdekaan 1/33 Cikokol Kota Tangerang TLP. 55793251, 55772949, 55793802, \\ 55736926 \\ e-mail: nofitri.heriyani@gmail.com
}

\begin{abstract}
Learning is a communication process between learners, teachers and teaching materials. Communication will not work without the aid of medium or message media. The message to be communicated is the content of the learning that is in the curriculum curricula poured by faculty or facilitator or other sources into communication symbols. Submission of learning messages from teachers to students today, still using teaching aids like books. This makes the students less interested and bored when absorbing the lesson thus giving the effect of lazy learning. Applications are made a medium of learning for elementary school students with references from books containing human anatomy material including the structure of the human body, skeletons and skin, muscular system, nervous system, endocrine system, respiratory, system cardio-vascular system, lymphatic system, digestive system, excretion system and reproduction system and contains anatomy learning information of the human body in detail in terms of material and images. The results of the study found that still using the use of books and media sculpture in the process of teaching and learning activities at the school. To support this application also included exercise questions, in order to find out how far the ability of students to deepen the material obtained from this application. This application development method uses Rapid Aplication Develpoment which consists of three phases namely planning, design workshop, and implementation with UML process design (Unified Modeling Language) and developed using the Eclipse IDE for data collection with literature and questioner studies, based on the results of research, applications that have been made is needed and greatly facilitates the children to learn the anatomy of the human body.
\end{abstract}

Keywords: Learning, Android App, Rapid Application Development (RAD), UML (Unified Modeling Language), Anatomy of Human Body

\section{PENDAHULUAN}

\section{Latar Belakang Masalah}

Pembelajaran adalah sebuah proses komunikasi antara pembelajar, pengajar dan bahan ajar. Komunikasi tidak akan berjalan tanpa bantuan sarana penyampain pesan atau media. Pesan yang akan dikomunikasikan adalah isi pembelajaran yang ada dalam kurikulum yang dituangkan oleh pengajar atau fasilitator atau sumber lain ke dalam simbolsimbol komunikasi. Penyampaian pesan pembelajaran dari guru kepada siswa saat ini, masih menggunakan alat bantu mengajar seperti buku. Hal ini menjadikan siswa kurang tertarik dan merasa bosan ketika menyerap pelajaran, sehingga memberikan efek malas belajar. Dan hal ini sangat jauh dari tujuan utama pembelajaran untuk mencetak peserta didik yang berkualitas. Penggunaan media dalam pembelajaran dapat membantu anak dalam memberikan pengalaman yang bermakna bagi siswa. Penggunaan media dalam pembelajaran dapat mempermudah siswa dalam memahami sesuatu yang abstrak menjadi lebih konkrit.

Berdasarkan masalah diatas peneliti mencoba untuk membuat sebuah aplikasi sebagai sarana pembelajaran untuk mempelajari materi tentang anatomi tubuh 
manusia bagi siswa sekolah dasar berbasis android. Aplikasi ini berisi materi tentang struktur tubuh manusia, kerangka dan kulit, sistem otot, sistem syaraf, sistem endokrin, sistem pernafasan, sistem kardio-vaskuler, sistem limfatik, sistem pencernaan, sistem eksresi dan sistem reproduksi pada manusia yang disajikan dengan tampilan yang menarik untuk mendukung media pembelajaran, sehingga siswa tidak mudah bosan dan tertarik dengan materi yang disajikan.

\section{Batasan Masalah}

Aplikasi pembelajaran ini diharap mampu mempermudah siswa dalam menyerap materi, maka penulis memberikan batasan masalah, yaitu:

1. Aplikasi yang dibuat merupakan media pembelajaran untuk siswa Sekolah Dasar dengan referensi dari buku "IImu Pengetahuan Alam untuk SD kelas 4, Pendamping Tematik Terpadu Ilmu Pengetahuan Alam Jilid 5 untuk SD Kelas 5 dan Anatomi Manusia: Bagaimana Tubuh Kita Bekerja".

2. Aplikasi yang dibuat berisi materi anatomi tubuh manusia diantaranya struktur tubuh manusia, kerangka dan kulit, sistem otot, sistem saraf, sistem endokrin, sistem pernafasan, sistem kardio-vaskuler, sistem limfatik, sistem pencernaan, sistem eksresi dan sistem reproduksi.

3. Aplikasi ini berisi informasi pembelajaran anatomi tubuh manusia secara terperinci beserta dalam bentuk materi dan gambar.

4. Pembuatan aplikasi ini menggunakan Software pendukung Eclipse yang berbasis android versi 3.8.0.

5. Metodelogi yang digunakan adalah RAD (Rapid Aplications Developper) meliputi: perencanaan syarat-syarat, workshop desain, dan implementasi.

\section{Perumusan Masalah}

Berdasarkan identifikasi masalah dan batasan masalah, maka rumusan masalah dalam penelitian ini adalah:

1. Bagaimana merancang bangun aplikasi pembelajaran Anatomi Tubuh Manusia berbasis android?

2. Bagaimana merancang aplikasi pembelajaran anatomi tubuh manusia menggunakan UML (Unified Modelling Language)?

3. Bagaimana aplikasi pembelajaran Anatomi Tubuh Manusia pada smartphone berbasis android dapat digunakan dengan mudah (user friendly)?

\section{Tujuan dan Manfaat Penelitian}

Tujuan dari peneletian ini adalah:

1. Untuk meningkatkan minat belajar siswa SD tentang anatomi tubuh manusia.

2. Membuat aplikasi pembelajaran anatomi tubuh manusia untuk siswa SD dengan memanfaatkan smartphone android, dan memberikan kemudahan dalam penggunaannya dan lebih menarik.

Manfaat yang diperoleh dari hasil penelitian ini adalah:

a. Manfaat Praktis

1. Memudahkan siswa dalam mempelajari atau mengulang materi pembelajaran diluar jam pelajaran sekolah walaupun tanpa seorang pembimbing atau guru dimana saja dengan menggunakan smartphone android.

2. Sebagai alat bantu dalam pembelajaran pengenalan anatomi manusia untuk anak sekolah dasar dengan memanfaatkan teknologi mobile.

b. Manfaat Teoritis

1. Memanfaatkan perkembangan teknologi mobile yang sedang berkembang saat ini dengan optimal.

2. Agar pengetahuan tidak hilang.

\section{LANDASAN TEORI DAN KERANGKA PEMIKIRAN}

\section{Rancang Bangun}

Rancang bangun merupakan serangkaian prosedur untuk menerjemahkan hasil analisa dan sebuah sistem ke dalam bahasa pemrograman untuk mendeskripsikan dengan detail bagaimana komponen-komponen sistem di implementasikan. Sedangkan pengertian pembangunan/bangun sistem adalah kegiatan menciptakan sistem baru maupun mengganti atau memperbaiki sistem yang telah ada baik secara keseluruhan maupun sebagian.

\section{Media Pembelajaran}

Media berasal dari bahasa latin merupakan bentuk jamak dari "Medium" yang secara harafiah berarti "Perantara" atau "Pengantar" yaitu perantara atau pengantar sumber pesan dengan penerima pesan. Beberapa ahli memberikan definisi tentang media pembelajaran sebagai teknologi pembawa pesan yang dapat dimanfaatkan untuk keperluan pembelajaran. Media pembelajaran merupakan media yang digunakan dalam pembelajaran, yaitu meliputi alat bantu guru dalam mengajar serta sarana pembawa pesan dari sumber belajar ke penerima pesan belajar. Sebagai penyaji dan penyalur pesan, media 
belajar dalam hal-hal tertentu bisa mewakili guru menyajikan informasi belajar kepada siswa.

\section{METODOLOGI PENELITIAN}

\section{Jenis Penelitian}

Penelitian ini menggunakan penelitian deskriptif kualitatif. Data yang diperoleh dari menyebar kuesioner kepada 20 pengguna smartphone android dengan masing-masing 10 pertanyaan. Pada kuesioner ini, peneliti menggunakan metode kualitatif. Pemakaian kuesioner merupakan hal pokok untuk mengumpulkan data. Analisa data kualitatif didasarkan pada hasil kuesioner tersebut. Berikut alur kerangka pemikiran pada penelitian sebagai berikut:

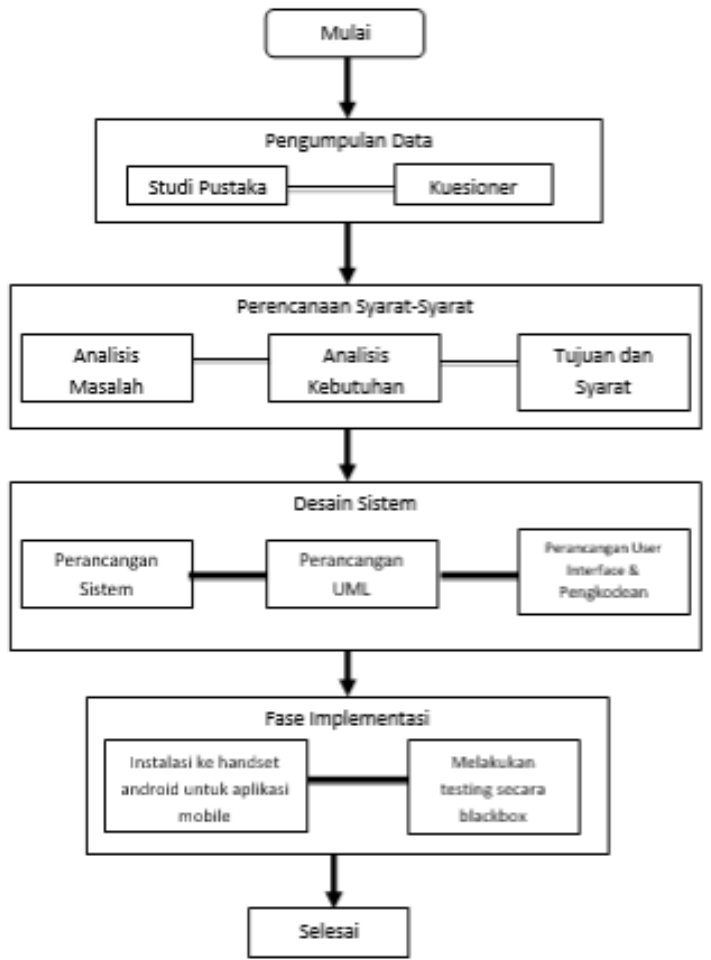

Gambar 3.1 Alur Kerangka Penelitian

\section{Metode Pengumpulan Data}

Metode pengumpulan data dapat dilakukan dengan beberapa cara yaitu observasi (pengamatan), kuesioner, dan studi pustaka. Data dan informasi yang dikumpulkan dalam penelitian ini adalah data primer dan data sekunder. Data primer diperoleh dengan menggunakan metode kuesioner yaitu Penulis melakukan kuesioner awal dan akhir dengan menyebar kuesioner kepada 20 pengguna smartphone android dengan masing-masing 10 pertanyaan. Pada kuesioner ini, peneliti menggunakan metode kualitatif. Pemakaian kuesioner merupakan hal pokok untuk mengumpulkan data. Analisa data kualitatif didasarkan pada hasil kuesioner tersebut. Sebuah kuesioner yang baik adalah yang mengandung pertanyaan-pertanyaan yang baik pula. Dalam arti pertanyaan yang diajukan sedemikian sehingga tidak menimbulkan interpretasi lain dari responden. Dengan melakukan kuesioner ini diharapkan dapat diketahuinya apakah aplikasi ini dibutuhkan dan juga untuk mengetahui apakah aplikasi yang telah dibuat oleh peneliti berjalan dengan baik atau tidak, dalam penelitian ini dipakai kuesioner bersifat tertutup dengan maksud bahwa jawaban kuesioner telah tersedia dan responden tinggal memilih beberapa alternatif yang telah disediakan. Sedangkan data sekunder didapatkan dati studi literatur, tulisan ilmiah tentang pembelajaran anatomi tubuh manusia yang ada dilingkungan sekolah dan internet.

\section{Metode Pengembangan Sistem RAD (Rapid Application Development) \\ RAD (Rapid Application Development)} adalah model proses pengembangan perangkat lunak yang bersifat inkremental terutama untuk waktu pengerjaan yang pendek. Model RAD adaptasi dari model air terjun versi kecepatan tinggi untuk pengembangan setiap komponen perangkat lunak. Rapid Aplication Development (RAD) yang dipakai peneliti memiliki tahapantahapan berikut:

\section{Fase Perencanaan Syarat-Syarat}

Dalam fase ini peneliti melakukan langkahlangkah kegiatan yaitu:

a. Identifikasi analisis sistem berjalan. Penulis mengidentifikasi analisis sistem yang sedang berjalan di aplikasi pembelajaran anatomi tubuh manusia yaitu media yang dapat digunakan dalam melakukan proses menampilkan materi dan gambar yang menarik bagi anak.

b. Mempelajari budaya pengguna smartphone android melalui website, buku-buku yang membahas android dan referensi pengembangan aplikasi android.

c. Menentukan tujuan pengembangan sistem. Dalam hal ini penulis menentukan tujuan yang harus dipenuhi dari sistem yang dibuat sehingga memuaskan pengguna.

d. Menentukan fitur-fitur sistem yang akan dibuat.

2. Workshop Design

Setelah disusun sistem yang ada termasuk penyelesaian kendala-kendala atau permasalahan-permasalahan yang ada, tahap selanjutnya adalah mendesain 
sistem yang diusulkan agar dapat berjalan lebih baik dan diharapkan dapat mengatasi masalah-masalah yang ada. Adapun metode desain yang digunakan terdiri dari beberapa tahapan, yaitu :

a. Fase Perancangan Pengguna, meliputi :

1. Perancangan Proses

Pada tahap perancangan proses, tools nya menggunakan diagramdiagram UML (Unified Modelling Language). Namun, tidak semua diagram yang disediakan oleh UML digunakan oleh penulis dalam perancangan sistem ini. Hanya beberapa diagram UML saja yang digunakan oleh penulis, yang menurut penulis dapat mendukung perancangan aplikasi ini. Adapun diagram yang digunakan oleh penulis adalah sebagai berikut :

a. Membuat Usecase Diagram, penulis mendeskripsikan kebutuhan-kebutuhan fungsional sistem.

b. Membuat Sequence Diagram, penulis menjelaskan secara detail urutan waktu dari pesan yang terjadi pada proses yang dilakukan sistem.

c. Membuat Activity Diagram, penulis menggambarkan alur aktifitas apa yang dilakukan user dan sistem, dan juga pandangan dalam bagaimana objek-objek bekerja.

d. Class merupakan sebuah spesifikasi yang jika diinstansiasi akan menghasilkan sebuah objek dan merupakan inti dari pengembangan dan desain berorientasi objek.

2. Perancangan Spesifikasi

Proses yang dibutuhkan, dengan menerjemahkan proses-proses yang terjadi didalam sistem ini kedalam bentuk algoritma sederhana yang akan diimplementasikan dalam bentuk program.

3. Perancangan Interface

Pada tahap perancangan interface, penulis merancang tampilan antarmuka yang sesuai dengan kebutuhan pengguna sehingga informasi ini dapat digunakan secara maksimal oleh para penggunanya. Dengan membuat rancangan layar tampilan yang berupa input-output yang bertujuan untuk memfasilitasi komunikasi antar user dengan sistem. Setelah rancangan layar tampilan terbentuk maka dilakukan tahap kontruksi.

b. Fase Konstruksi

Pada tahap ini merupakan presentasi dari hasil perancangan ke dalam program. Dalam tahap ini penulis menggunakan bahasa pemrograman java dengan menggunakan IDE Eclipse versi 3.8.0 -v2.10.0-519525 dan menggunakan emulator Genymotion dengan versi 2.10.0-vbox.

Berikut adalah tahapan-tahapan dalam fase implementasi, sebagai berikut:

1. Tahapan ini merupakan presentasi dari hasil perancangan ke dalam program. Penelitian menggunakan java JDK (Java Development Kit) sebagai bahasa pemrograman yang di integrasikan ke dalam IDE Eclipse, serta Android SDK, dilanjutkan dengan instalasi ke handset android.

2. Melakukan pengujian atau testing aplikasi secara black box yaitu menguji pada guru Sekolah Dasar (SD), orang tua murid Sekolah Dasar (SD), dan juga anaknya. Hal ini dilakukan supaya mengetahui fungsi yang ditentukan dimana produk dirancang sesuai dengan keinginan user, pengujiannya dilakukan untuk memperlihatkan bahwa masing-masing fungsi beroperasi sepenuhnya. Untuk native application akan di install pada beberapa handset android dari beberapa merk dan beberapa level operating system android.

\section{Alasan Menggunakan RAD (Rapid Application Development) \\ Dari beberapa model perangkat lunak yang} di pilih yaitu model RAD sebagai metode pengembangan sistem dengan alasan sebagai berikut:

1. Kebutuhan perangkat lunak dipahami dengan baik dan lingkup perangkat lunak dibatasi dengan baik sehingga dapat menyelesaikan pembuatan perangkat lunak dengan waktu yang pendek, jika kebutuhan dapat dipahami dengan baik.

2. Model RAD membagi tim pengembang menjadi beberapa tim untuk mengerjakan beberapa komponen yang masing-masing pengerjaan dapat dilakukan secara paralel.

3. Model RAD memiliki kelemahan dalam membuat sistem perangkat lunak untuk sekala besar. Maka model RAD akan memerlukan sumber daya manusia yang cukup besar untuk membentuk tim-tim yang mengembangkan komponen-komponen. 


\section{PEMBAHASAN}

\section{Metode Pengembangan Sistem}

Untuk analisis dan perancangan sistem aplikasi ini, penulis menggunakan metode pengembangan sistem RAD (Rapid Application Development) yang terdiri atas fase perencanaan syarat-syarat, fase workshop desain, dan fase implementasi.

\section{Fase Perencanaan Syarat-Syarat}

Sebagaimana diuraikan pada bab sebelumnya, fase ini adalah fase dimana peneliti mengidentifikasi tujuan-tujuan aplikasi atau sistem serta mengidentifikasi syarat-syarat informasi yang ditimbulkan dari tujuan-tujuan tersebut.

a. Identifikasi Analisis Sistem Berjalan

Sistem analisis yang berjalan saat ini ialah masih terbilang manual yaitu dengan menggunakan buku tentang pembelajaran anatomi tubuh manusia ataupun alat peraga patung.

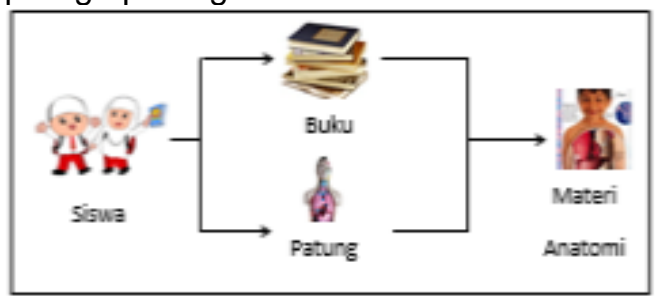

Gambar 4.1 Analisis Sistem Berjalan

Dari gambar 4.1 menjelaskan bahwa anak-anak atau guru masih menggunakan media pembelajaran buku atau alat peraga patung untuk mengenalkan nama-nama anatomi tubuh manusia dan beserta organ tubuh manusia.

b. Analisa Sistem Usulan

Dalam hal ini penulis berusaha membuat sebuah aplikasi pembelajaran anatomi tubuh manusia untuk anak sekolah dasar berbasis android yang berguna untuk membantu kepada semua kalangan untuk mengenalkan lebih jauh tentang materi anatomi tubuh manusia kepada anak. Aplikasi ini dirancang sebagai jalur alternatif untuk belajar kepada anak-anak yang dimana tidak usah perlu untuk membeli buku yang terlalu tebal dan lumayan mahal, cukup dengan menginstal aplikasi pembelajaran anatomi tubuh ini di perangkat android yang dimiliki para user maka langsung dapat menjalankan aplikasi ini sesuai dengan ketentuannya. Berikut adalah analisa dari usulan aplikasi tersebut:

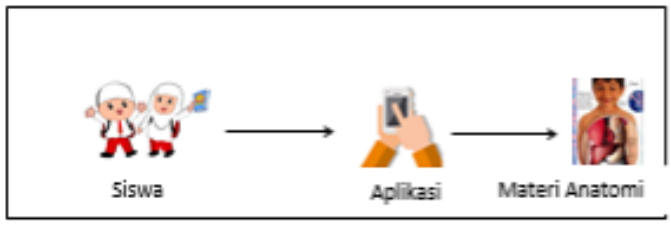

Gambar 4.2 Analisis Sistem Usulan

Dari gambar diatas menjelaskan bahwa media pembelajaran melalui smartphone berbasis android yang sudah terinstal aplikasi anak-anak dapat belajar materi anatomi tubuh manusia.

c. Menentukan fitur-fitur aplikasi

Menentukan fitur-fitur berdasarkan tujuantujuan aplikasi atau sistem serta mengidentifikasi syarat-syarat insformasi yang ditimbulkan dari tujuan-tujuan tersebut. Berikut adalah fitur-fitur yang akan dikembangkan dalam aplikasi:

1. Menampilkan materi-materi anatomi tubuh manusia berdasarkan kategorikategori berisi materi tentang struktur tubuh manusia, kerangka dan kulit, sistem otot, sistem saraf, sistem endokrin, sistem pernafasan, sistem kardio-vaskuler, sistem limfatik, sistem pencernaan, sistem eksresi dan sistem reproduksi pada manusia.

2. Menampilkan fitur list materi video pembelajaran.

3. Menampilkan menu latihan soal

\section{Fase Workshop Desain}

Setelah identifikasi fitur-fitur yang ada, tahap selanjutnya adalah mendesain sistem yang dikembangkan agar dapat berjalan dengan baik dan diharapkan dapat mengatasi masalah yang ada. Tahapan yang dilakukan sebagai berikut:

a. Perancangan menggunakan UML (Unified Modeling Language)

Pada tahap perancangan proses, tools nya menggunakan diagram-diagram UML (Unified Modeling Language). Namun, tidak semua diagram yang disediakan oleh UML digunakan oleh penulis dalam perancangan sistem ini. Hanya beberapa diagram UML saja yang digunakan oleh penulis, yang menurut penulis dapat mendukung perancangan aplikasi ini. Adapun diagram yang digunakan oleh penulis adalah Use Case Diagram, Use Case Scenario, Activity Diagram, Sequence Diagram dan Class Diagram.

b. Pembuatan Use Case Diagram

Use Case Diagram ini mendeskripsikan interaksi antara user dengan sistem di dalam 
sistem aplikasi pembelajaran anatomi tubuh manusia.

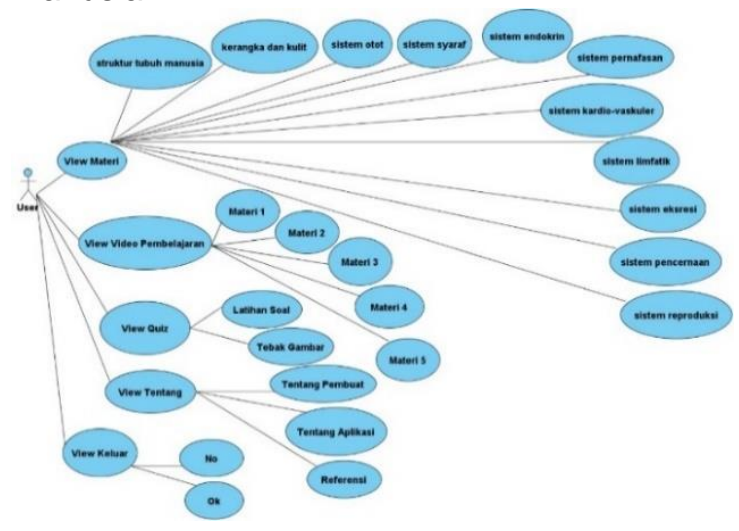

\section{Gambar 4.3 Use Case Diagram Anatomi Tubuh Manusia}

Pada gambar 4.3 Use Case Diagram dimana User dapat mengakses menu aplikasi secara keseluruhan.

\section{c. Pembuatan Activity Diagram}

Activity diagram menggambarkan aktifitas yang terjadi dalam aplikasi anatomi tubuh manusia dari aktifitas dimulai sampai dengan aktifitas terhenti.

\section{Activity Diagram Materi}

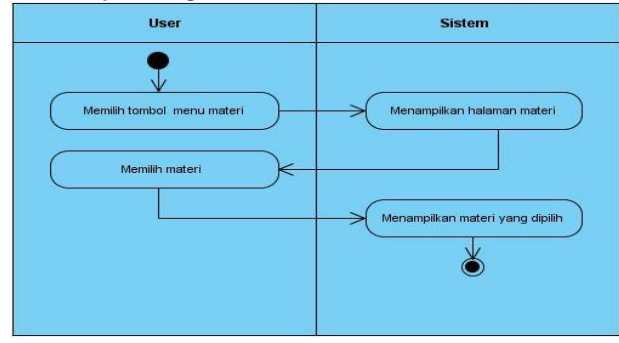

Gambar 4.4 Activity Diagram Materi

Pada gambar 4.4 menjelaskan aktifitas seorang user untuk melihat materi yang terdapat di aplikasi ini. Proses awal adalah user memilih tombol menu materi yang terdapat pada halaman menu utama. Berikutnya sistem akan menampilkan halaman materi, kemudian user memilih salah satu materi yang dipilih.

\section{Activity Diagram Video Pembelajaran}

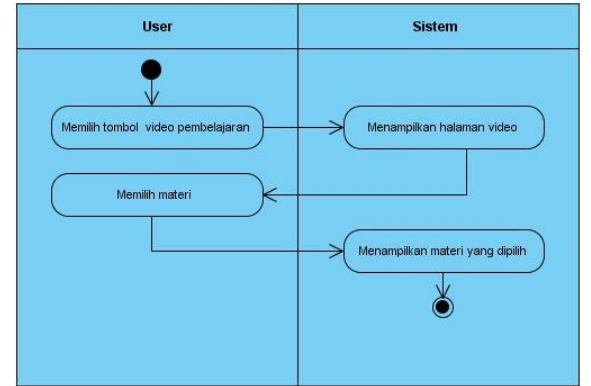

Gambar 4.5 Activity Diagram Video Pembelajaran

Pada gambar 4.5 menjelaskan aktifitas seorang user untuk melihat menu video pembelajaran yang terdapat di aplikasi ini. Proses awal adalah user memilih tombol menu video pembelajaran yang terdapat pada halaman menu utama. Berikutnya sistem akan menampilkan halaman video berisikan materi video, kemudian user memilih salah satu materi yang dipilih.

3. Activity Diagram Quiz

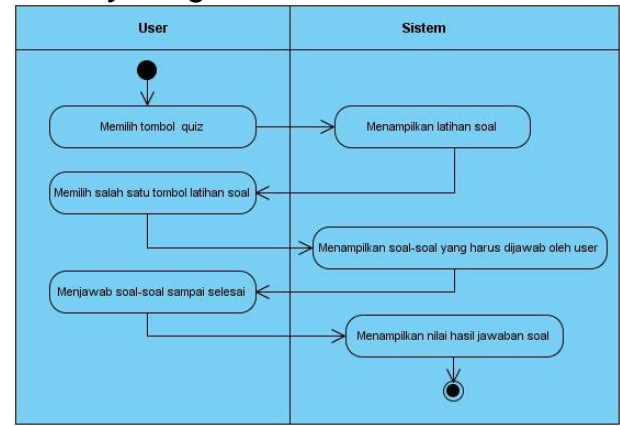

Gambar 4.6 Activity Diagram Quiz

Pada gambar 4.6 menjelaskan aktifitas seorang user untuk melihat menu quiz yang terdapat di aplikasi ini. Proses awal adalah user memilih menu tombol quiz yang terdapat pada halaman menu utama. Berikutnya sistem akan menampilkan latihan soal yang berisikan latihan soal dan tebak gambar, kemudian user memilih salah satu tombol latihan soal dan kemudian sistem akan menampilkan soal-soal yang harus dijawab oleh user dan kemudian user menjawab soal-soal sampai selesai, setelah itu Sistem akan menampilkan nilai hasil jawaban soal.

d. Pembuatan Sequence Diagram

Sequence Diagram ini menjelaskan secara detail urutan proses yang dilakukan dalam sistem untuk mencapai tujuan dari use case, 
digambarkan pada sequence diagram berikut.

1. Sequence Diagram Materi

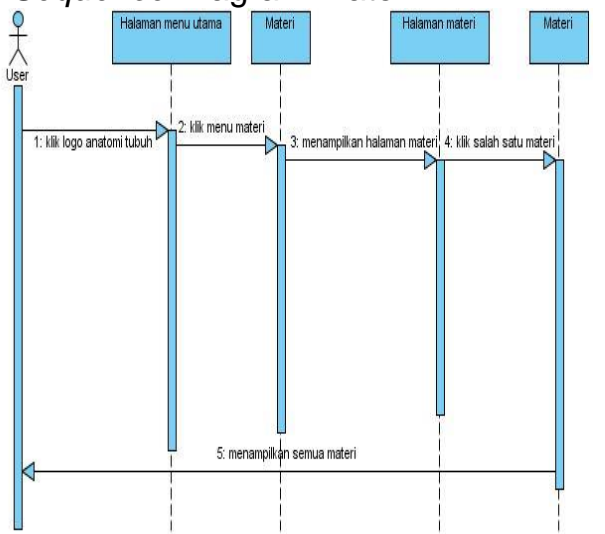

Gambar 4.7 Sequence Diagram Materi

Sequence diagram pada gambar 4.7 menjelaskan tentang proses user yang akan melihat materi berdasarkan list materi (Struktur tubuh manusia, sistem otot, kerangka dan kulit, sistem pencernaan, sistem pernafasan, sistem endokrin, sistem kardio-vaskuler, sistem limfatik, sistem eksresi, sistem saraf dan sistem reproduksi) yang user inginkan. Prosesnya adalah user mengklik logo anatomi tubuh lalu akan muncul halaman menu utama, kemudian user memilih menu materi lalu akan muncul halaman materi. setelah itu user memilih salah satu materi maka akan muncul materi yang telah user pilih

2. Sequence Diagram Video Pembelajaran

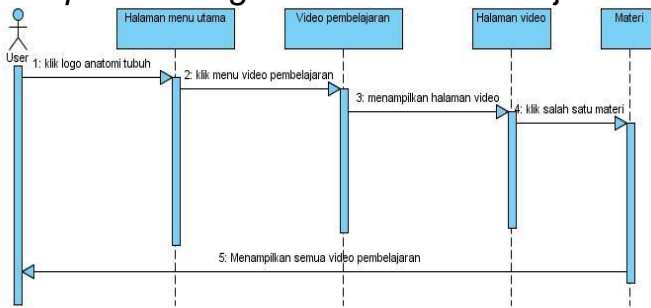

Gambar 4.8 Sequence Diagram Video Pembelajaran

Sequence diagram pada gambar 4.8 menjelaskan tentang proses user yang akan melihat video pembelajaran berdasarkan list materi video (materi 1 , materi 2, materi 3, materi 4 dan materi 5) yang user inginkan. Prosesnya adalah user mengklik logo anatomi tubuh lalu akan muncul halaman menu utama, kemudian user memilih menu video pembelajaran lalu akan muncul halaman video. Kemudian user memilih salah satu materi maka akan muncul materi yang telah user pilih.
3. Sequence Diagram Quiz

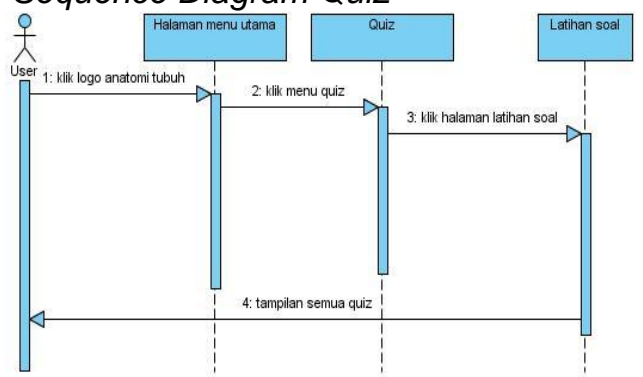

Gambar 4.9 Sequence Diagram Quiz

Sequence diagram pada gambar 4.9 menjelaskan tentang proses user yang akan melihat tampilan quiz berdasarkan list latihan soal (latihan soal dan tebak gambar) yang user inginkan. Prosesnya adalah user mengklik logo anatomi tubuh lalu akan muncul halaman menu utama, kemudian user memilih menu quiz lalu akan muncul halaman latihan soal. Kemudian user memilih salah satu menu latihan soal dan kemudian akan muncul soal-soal yang harus di jawab oleh user.

e. Pembuatan Class Diagram

Berikut adalah Class Diagram yang diusulkan:

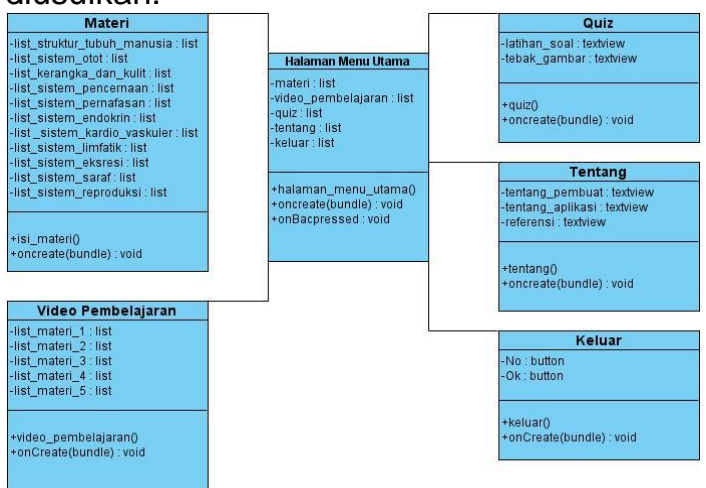

Gambar 4.10 Class Diagram Aplikasi Anatomi Tubuh Manusia

\section{Hasil Kuesioner}

Dari hasil pengumpulan data berupa kuesioner, Penulis menguraikan pertanyaan-pertanyaan dan hasil kuesioner yang berhubungan untuk membangun aplikasi pembelajaran anatomi tubuh manusia kepada 20 responden yaitu orang tua siswa Sekolah Dasar Negeri Cihuni 1 yang terdiri masing-masing 10 pertanyaan.

\begin{tabular}{|l|c|c|}
\hline \multicolumn{1}{|c|}{ Keterangan } & \multicolumn{2}{|c|}{ Hasil Responden } \\
\cline { 2 - 3 } & Ya & Tidak \\
\hline $\begin{array}{l}\text { Mengenal Anatomi Tubuh } \\
\text { Manusia? }\end{array}$ & $50 \%$ & $50 \%$ \\
\hline Mengetahui nama-nama & 0 & $100 \%$ \\
\hline
\end{tabular}




\begin{tabular}{|l|l|l|}
\hline $\begin{array}{l}\text { dan bagian anatomi } \\
\text { tubuh? }\end{array}$ & \\
\hline $\begin{array}{l}\text { Berapa banyak nama- } \\
\text { nama bagian tubuh } \\
\text { manusia yang diketahui } \\
\text { anak-anak? }\end{array}$ & & $60 \%$ \\
\hline $\begin{array}{l}\text { Tahukah anak-anak } \\
\text { tentang materi struktur } \\
\text { anatomi tubuh manusia? }\end{array}$ & $50 \%$ & $50 \%$ \\
\hline $\begin{array}{l}\text { Apakah alat peraga } \\
\text { patung efektif untuk } \\
\text { pembelajaran anatomi } \\
\text { tubuh manusia bagi anak- } \\
\text { anak? pembelajaran }\end{array}$ & & \\
\hline $\begin{array}{l}\text { Apakah buku paket efektif } \\
\text { untuk tubuh manusia } \\
\text { anatomi tubuh } \\
\text { untuk anak-anak? }\end{array}$ & & \\
\hline $\begin{array}{l}\text { Apakah perlu anak-anak } \\
\text { mengetahui nama-nama } \\
\text { anatomi tubuh manusi? }\end{array}$ & $90 \%$ & \\
\hline $\begin{array}{l}\text { Apakah aplikasi anatomi } \\
\text { tubuh manusia sangat } \\
\text { efektif sebagai media } \\
\text { untuk pembelajaran untuk } \\
\text { mengenalkan nama- } \\
\text { nama anatomi tubuh } \\
\text { manusia kepada anak? }\end{array}$ & & \\
\hline $\begin{array}{l}\text { Apakah visualisasi sangat } \\
\text { efektif untuk } \\
\text { mengenalkan nama- } \\
\text { nama anatomi tubuh } \\
\text { manusia bagi anak-anak? }\end{array}$ & $75 \%$ & $10 \%$ \\
\hline $\begin{array}{l}\text { Seberapa penting } \\
\text { anatomi tubuh manusia di } \\
\text { smartphone? }\end{array}$ & $85 \%$ \\
\hline
\end{tabular}

\section{Implementasi}

Sebelum program diimplementasikan, maka program harus bebas dari kesalahan. Kesalahan program yang mungkin terjadi antara lain karena kesalahan penulisan (Coding), kesalahan proses atau kesalahan logika. Dalam tahap implementasi Rancang Bangun Sistem Informasi Pembelajaran Anatomi Tubuh Manusia Pada Sekolah Dasar Negeri Cihuni 1 Berbasis Android ini, analisis kebutuhan perangkat pendukung menjadi hal yang sangat penting. Sistem ini dapat berjalan dengan baik, apabila mampu berjalan lancar pada hardware (handset smartphone android). Selain itu kebutuhan perangkat lunak pendukung juga harus tersedia demi kelancaran tahap implementasi program.

Dalam proses implementasi ini ada beberapa langkah yang dilakukan yaitu:

1. Memasukan kode program (coding), tahap ini dilakukan dengan menggunakan program pengembangan aplikasi android, yaitu IDE Eclipse, Android Developer Tools (ADT), Android SDK (Software Development Kit) dan Geny Motion sebagai emulator.

2. Melakukan pemaketan dengan menggunakan fasilitas yang disediakan oleh android SDK.

3. Menguji program dengan menggunakan handset smartphone android.

\section{Implementasi Perangkat Lunak}

Perangkat lunak yang digunakan dalam membangun aplikasi ini adalah sebagai berikut:

Tabel 4.1 Implementasi perangkat Lunak

\begin{tabular}{|l|l|}
\hline \multicolumn{2}{|c|}{ SOFTWARE INFORMATION } \\
\hline \multicolumn{1}{|c|}{ Software } & \multicolumn{1}{c|}{ Versi } \\
\hline IDE Eclipse & 3.08.0.v20120607 \\
\hline $\begin{array}{l}\text { Java SE } \\
\text { Development KIT 8 } \\
\text { UPDATE 31 (64BIT) }\end{array}$ & 8.0 .310 .13 \\
\hline $\begin{array}{l}\text { Geny Motion } \\
\text { Emulator }\end{array}$ & -2.10 .0 -vbox \\
\hline $\begin{array}{l}\text { Adobe Dreamweaver } \\
\text { CS3 }\end{array}$ & $\begin{array}{l}\text { Adobe Master } \\
\text { Collection CS3 1.0 }\end{array}$ \\
\hline
\end{tabular}

\section{Implementasi Perangkat Keras}

Perangkat keras yang digunakan dalam membangun aplikasi ini sebagai berikut:

Tabel 4.2 Implementasi perangkat Keras

\begin{tabular}{|c|c|}
\hline \multicolumn{2}{|c|}{ SISTEM INFORMATION } \\
\hline $\begin{array}{l}\text { Computer } \\
\text { Name }\end{array}$ & ACER-PC \\
\hline System Model & Aspire V5-431 \\
\hline Processor & $\begin{array}{l}\text { Intel囚 Celeron® CPU } \\
1007 \mathrm{~B}{ }^{\circledR} 1.50 \mathrm{GHz} \\
(2 \mathrm{CPUs}), \sim 1.5 \mathrm{GHz}\end{array}$ \\
\hline Bios & Phoenix BIOS SC-T v2.2 \\
\hline Memory & 6144MB RAM available \\
\hline $\begin{array}{l}\text { DirectX } \\
\text { Version }\end{array}$ & DirectX 11 \\
\hline
\end{tabular}

3. Implementasi

Smartphone

yang

Digunakan

Perangkat smartphone yang digunakan dalam membangun aplikasi ini mengunakan smartphone sebagai berikut:

Tabel 4.3 Implementasi Smartphone Yang Digunakan

\begin{tabular}{|l|l|}
\hline \multicolumn{2}{|c|}{ SMARTPHONE INFORMATION } \\
\hline Software & Versi \\
\hline Samsung Grand Prime & $\begin{array}{l}\text { Android Version 5.0.2 } \\
\text { Lollipop }\end{array}$ \\
\hline Model Number & SM-G530H \\
\hline Kernel Version & $\begin{array}{l}3.10 .49 .-1044045 \\
\text { dpi@SWDD6618 \#1 }\end{array}$ \\
\hline
\end{tabular}




\begin{tabular}{|l|l|}
\hline Memory & Internal 8 GB \\
\hline RAM & 1 GB \\
\hline Layar & $\begin{array}{l}\text { TFT capacitive } \\
\text { Touchscreen 540x960 } \\
\text { pixel, 5,0 Inches }\end{array}$ \\
\hline
\end{tabular}

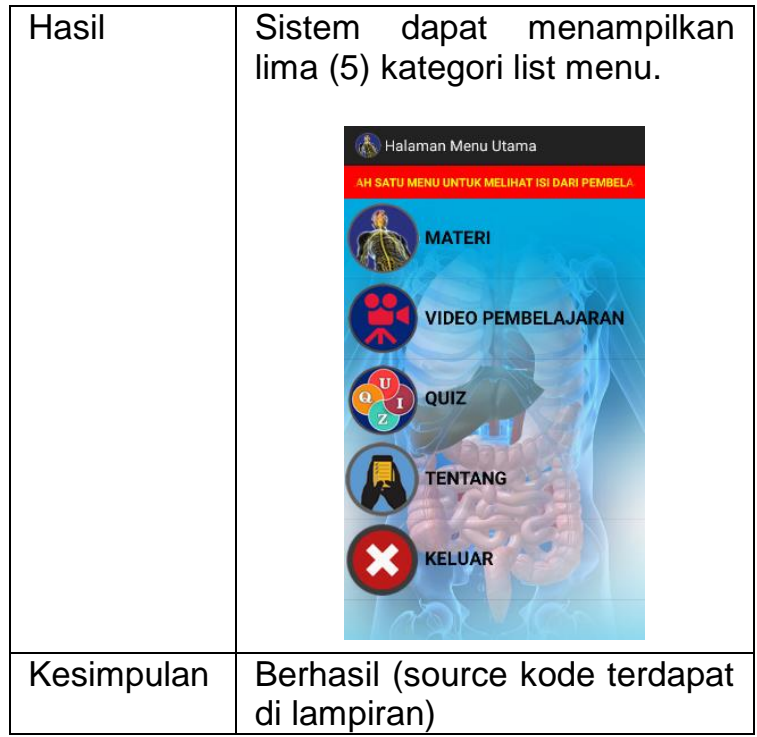

\section{Pengujian Sistem}

Pengujian merupakan bagian yang penting dalam siklus pembangunan perangkat lunak. Tujuan dari pengujian adalah untuk menjamin perangkat lunak yang dibangun memiliki kualitas yang handal, yaitu mampu mempersentasikan kajian pokok dari spesifikasi, analisis, perancangan, dan pengkodean dari perangkat lunak itu sendiri.

Tabel 4.4 Pengujian Tampilan Pembuka (Splash Screen)

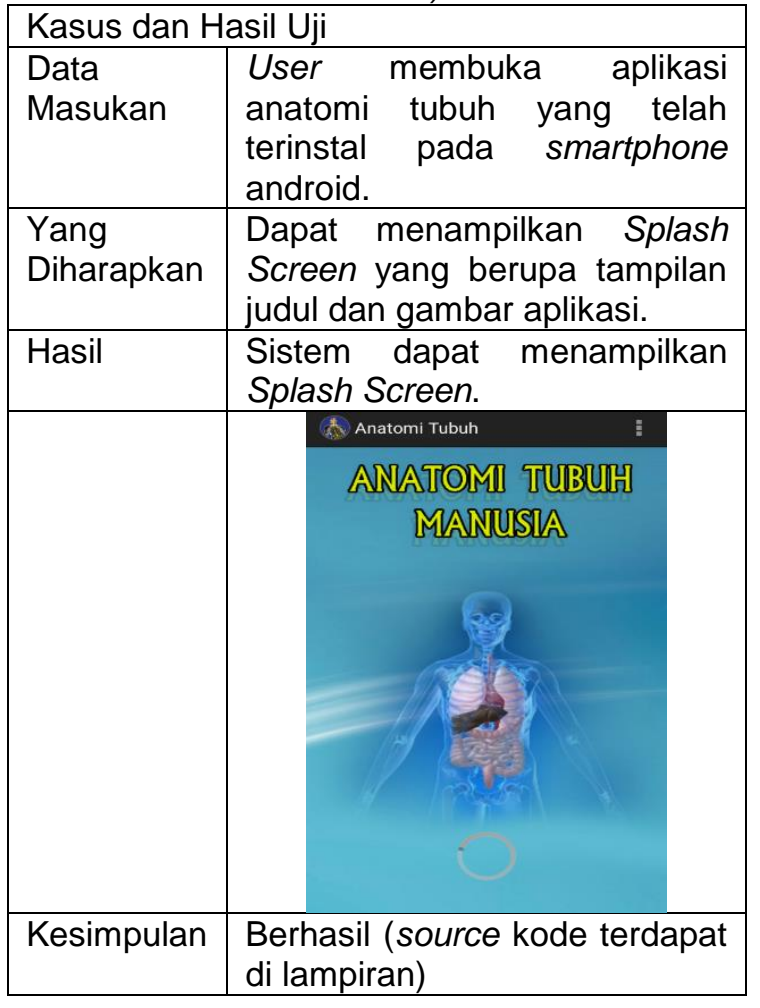

Tabel 4.5 Pengujian Halaman Menu Utama

\begin{tabular}{|l|l|l|}
\hline Kasus dan Hasil Uji \\
\hline Data & $\begin{array}{l}\text { User membuka aplikasi } \\
\text { anatomi tubuh yang telah } \\
\text { terinstal pada smartphone } \\
\text { android. }\end{array}$ \\
\hline $\begin{array}{l}\text { Yang } \\
\text { Diharapkan }\end{array}$ & $\begin{array}{l}\text { Dapat menampilkan halaman } \\
\text { menu utama yang berupa } \\
\text { tampilan list menu-menu } \\
\text { pilihan. }\end{array}$ \\
\hline
\end{tabular}

Tabel 4.7 Pengujian Halaman Materi

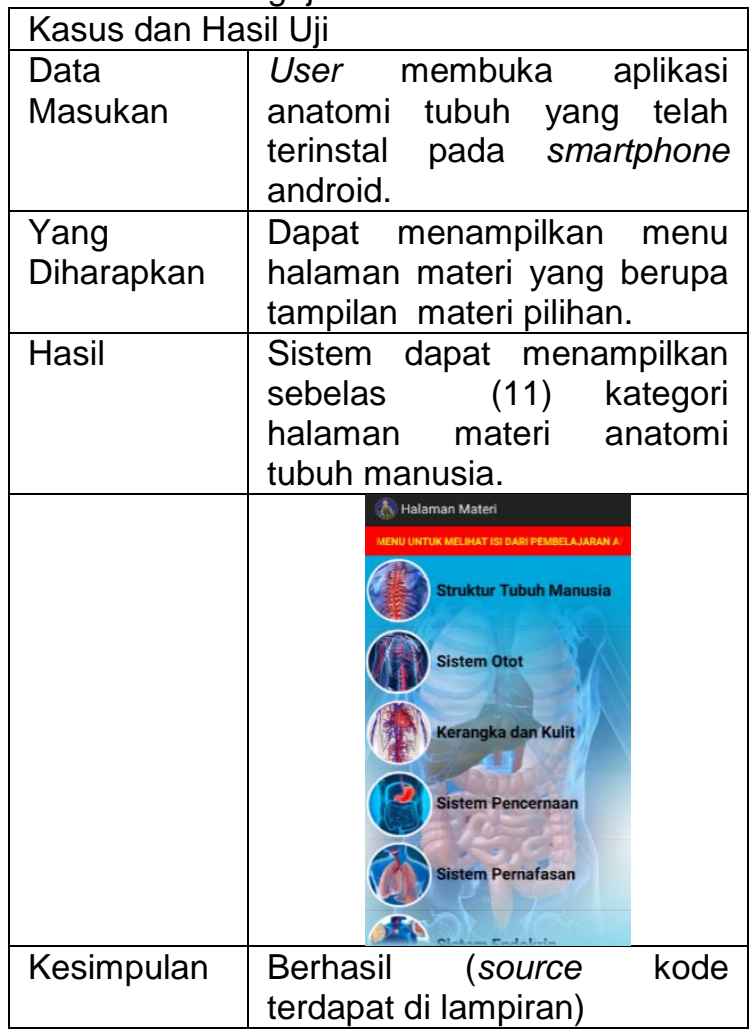

Tabel 4.8 Pengujian Tampilan Materi

\begin{tabular}{|l|llr|}
\hline \multicolumn{3}{|l|}{ Kasus dan Hasil Uji } & \\
\hline Data & User membuka & aplikasi \\
Masukan & anatomi & tubuh kemudian \\
& masuk ke menu materi dan \\
& terdapat beberapa tampilan \\
& menu & halaman materi \\
& kemudian pilih salah satu \\
& materi yang tersedia. \\
\hline
\end{tabular}




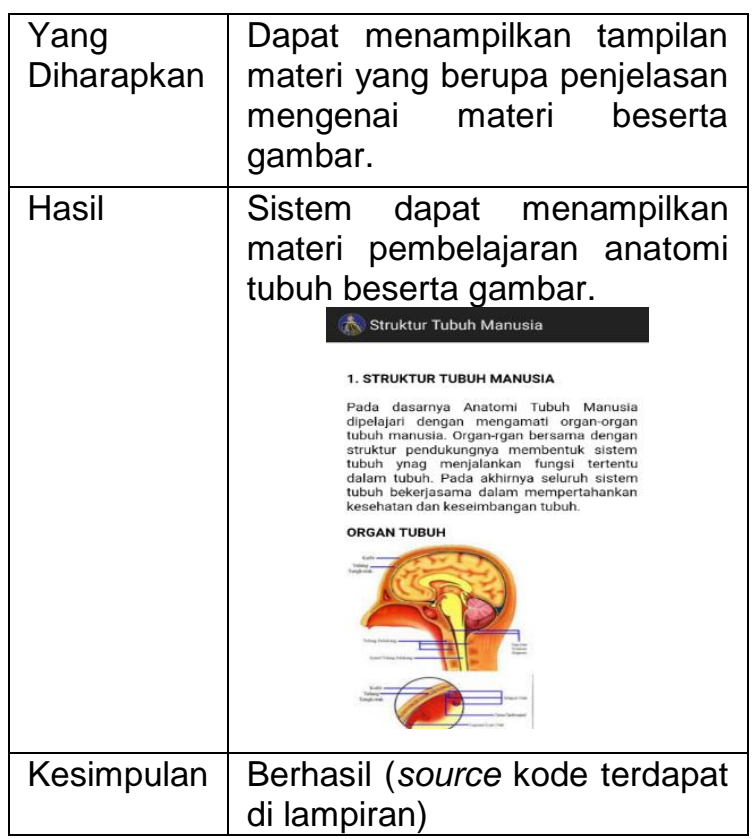

Tabel 4.9 Pengujian Menu Video Pembelajaran

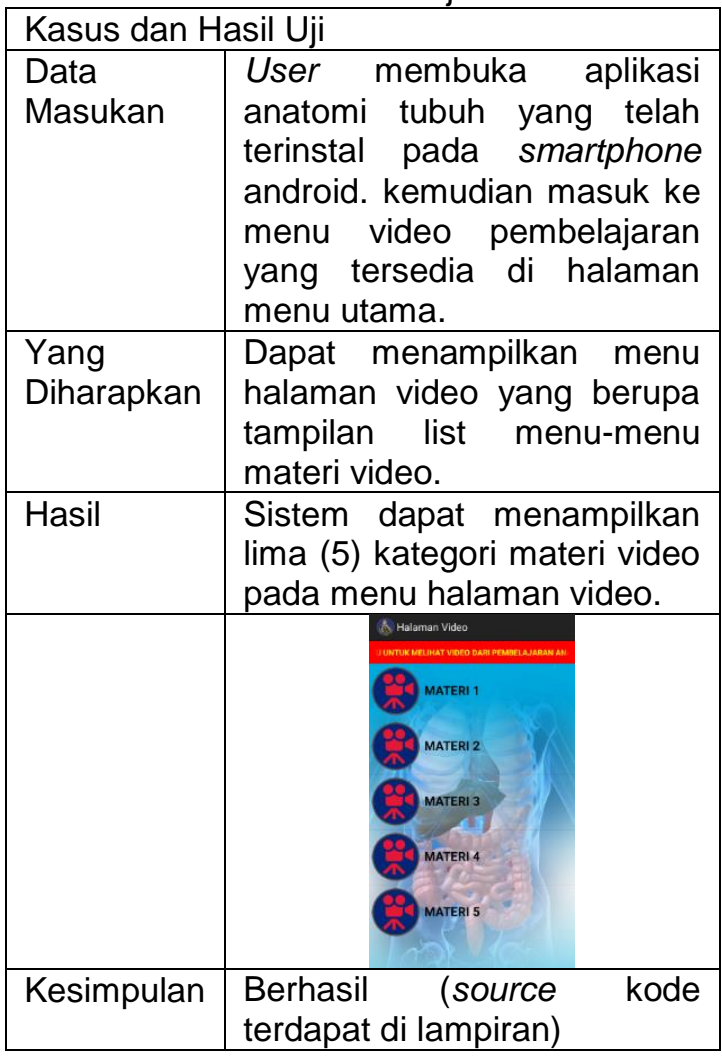

Tabel 4.10 Pengujian Tampilan Materi Video

\begin{tabular}{|l|l|r|}
\hline Kasus dan Hasil Uji \\
\hline Data & User membuka aplikasi \\
Masukan & anatomi tubuh kemudian \\
& masuk ke menu video \\
& pembelajaran dan terdapat \\
& beberapa tampilan menu \\
\hline
\end{tabular}

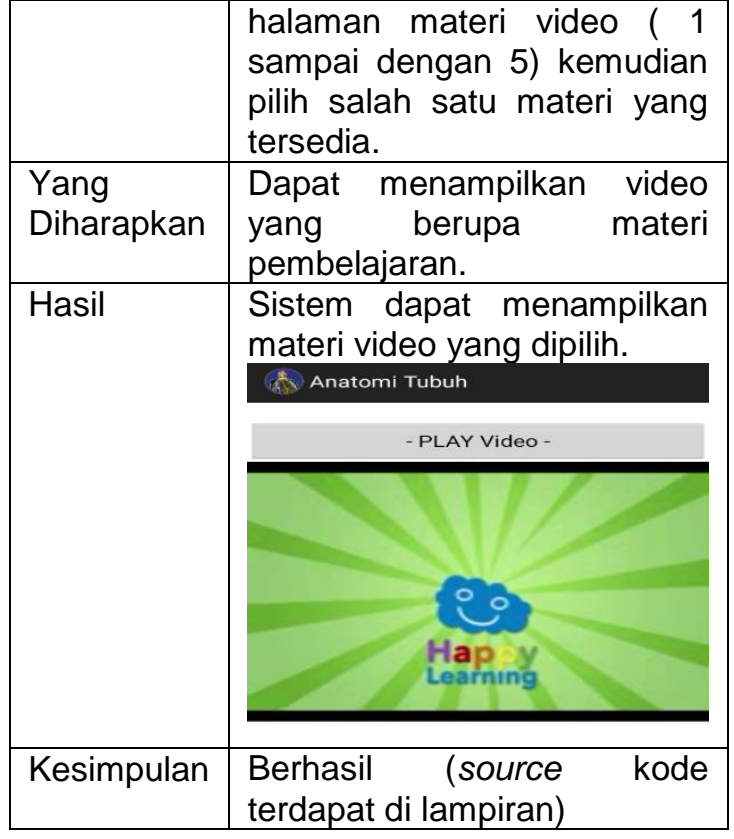

Tabel 4.11 Pengujian Menu Quiz

\begin{tabular}{|l|l|}
\hline Kasus dan Hasil Uji \\
Masukan & $\begin{array}{l}\text { User membuka aplikasi } \\
\text { anatomi tubuh kemudian } \\
\text { masuk ke menu quiz dan } \\
\text { terdapat tampilan menu } \\
\text { latihan soal kemudian pilih } \\
\text { salah satu latihan soal yang } \\
\text { tersedia. }\end{array}$ \\
\hline $\begin{array}{l}\text { Yang } \\
\text { Diharapkan }\end{array}$ & $\begin{array}{l}\text { Dapat menampilkan menu } \\
\text { latihan soal yang berupa } \\
\text { tampilan menu-menu yang } \\
\text { dipilih. }\end{array}$ \\
\hline Hasil & $\begin{array}{l}\text { Sistem dapat menampilkan } \\
\text { dua (2) kategori latihan soal } \\
\text { yang dipilih. }\end{array}$ \\
\hline Kesimpulan & $\begin{array}{l}\text { Berhasil (source kode terdapat } \\
\text { di lampiran) }\end{array}$ \\
\hline
\end{tabular}

Tabel 4.12 Pengujian Tampilan Quiz

\begin{tabular}{|l|lcr|}
\hline Kasus dan Hasil Uji & & \\
\hline Data & User membuka & aplikasi \\
Masukan & anatomi & tubuh & kemudian \\
& masuk ke menu quiz dan \\
& terdapat menu latihan soal \\
& kemudian pilih salah satu menu \\
\hline
\end{tabular}




\begin{tabular}{|l|l|}
\hline Yang & latihan soal yang dipilih. \\
\hline Diharapkan & $\begin{array}{l}\text { Dapat menampilkan tampilan } \\
\text { quiz pada halaman menu } \\
\text { latihan soal yang berupa soal- } \\
\text { soal yang harus dijawab oleh } \\
\text { user. }\end{array}$ \\
\hline Hasil & $\begin{array}{l}\text { Sistem dapat menampilkan } \\
\text { soal-soal latihan. } \\
\text { somin }\end{array}$ \\
\hline Kesimpulan & $\begin{array}{l}\text { Berhasil (source kode terdapat } \\
\text { di lampiran) }\end{array}$ \\
\hline
\end{tabular}

Tabel 4.13 Pengujian Tampilan Nilai

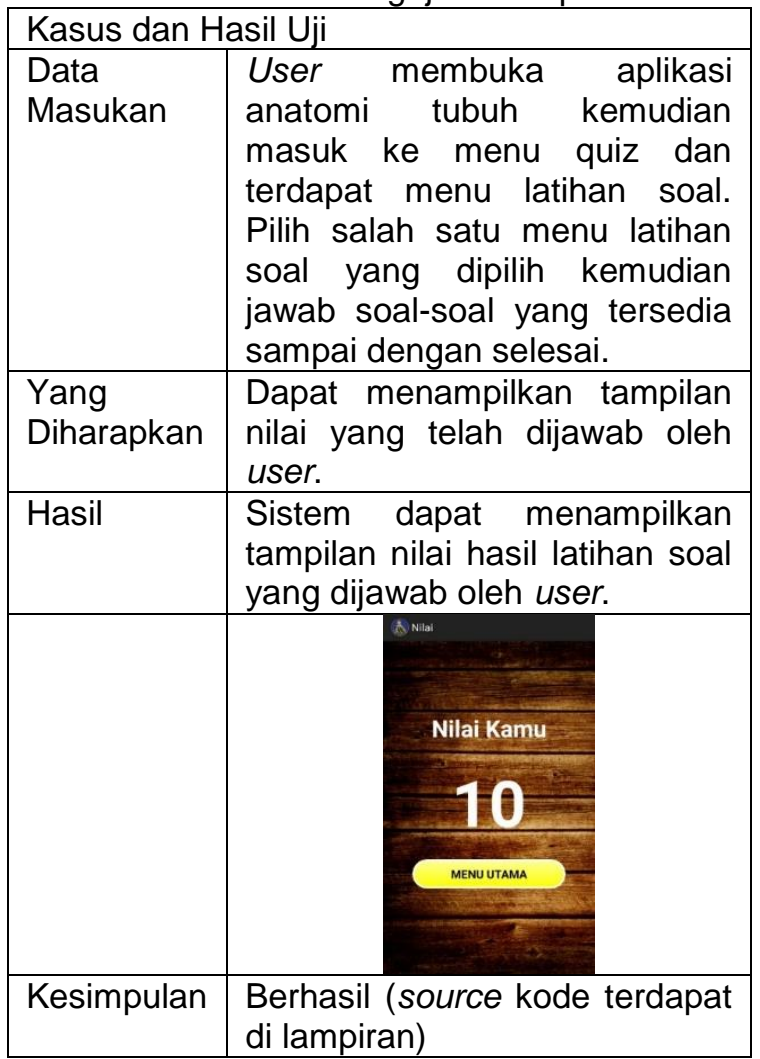

Dari hasil pengujian dengan kasus sampel yang telah dilakukan memberikan kesimpulan bahwa secara fungsional sistem dapat menghasilkan output yang diharapkan.

\section{PENUTUP}

\section{KESIMPULAN}

Dari hasil penelitian yang dilakukan oleh penulis terhadap rancang bangun sistem informasi pembelajaran anatomi tubuh manusia berbasis android yakni:

1. Pembuatan aplikasi pembelajaran anatomi tubuh manusia ini dilakukan dengan beberapa langkah yang harus diselesaikan. Dengan menggunakan perangkat pendukung (Software) IDE Eclipse versi 3.8.0, Java SDK (Software Development Kit) dan Genymotion sebagai emulator pendukung. Serta untuk pengembangan sistemnya menggunakan Metodologi RAD (Rapid Aplication Development). Pertama tahapan identifikasi masalah yang terjadi, sehingga akan mendapatkan permasalahan yang dialami user. Untuk mendapatkan pemecahan masalah tersebut.

2. Merancang aplikasi dengan pendekatan UML (Unified Modelling Language) meliputi Use Case Diagram, Use Case Scenario, Activity Diagram, Sequence Diagram dan Class Diagram, kemudian melakukan pengkodean sesuai dengan perancangan yang sudah dibuat. Pada langkah berikutnya yaitu mengimplementasikan dan menguji aplikasi supaya aplikasi tersebut bisa digunakan sesuai harapan.

3. Dengan adanya aplikasi media pendukung pembelajaran ini diharapkan dapat mempermudah bagi anak-anak dalam memahami pembelajaran anatomi tubuh manusia pada mata pelajaran IImu Pengetahuan Alam (IPA) yang ada karena di dalam aplikasi sudah tersedia materi, video dan soal pilihan ganda beserta soal tebak gambar yang dapat menambah wawasan dari siswa. Aplikasi di buat user friendly agar siswa mudah menggunakannya.

\section{SARAN}

Aplikasi yang penulis buat tentu saja belum sempurna, masih banyak hal yang dapat dilakukan untuk mengembangakan aplikasi ini agar menjadi lebih baik lagi. Oleh karena itu penulis juga menyampaikan beberapa saran guna menambah nilai dan manfaat bagi penulisan, yaitu:

1. Diharapkan pada pengembangan selanjutnya aplikasi dapat menampilkan lebih luas tentang materi pembelajaran anatomi tubuh manusia.

2. Pengembangan juga dapat dilakukan lagi dengan menambahkan fitur animasi yang 
berkaitan dengan materi pembelajaran anatomi tubuh manusia.

3. Pengujian juga dapat dilakukan dengan menggunakan beberapa handphone lainnya yaitu Blackberry, iphone dan lain-lain.

\section{REFERENSI}

[1] Andi (2013), Android Programming With Eclipse, Yogyakarta: Wahana Komputer.

[2] Anofrizen \& Fadlan Alfi, 2015, Mobile Aplication Pembelajaran Interaktif Bahasa Inggris Berbasis Android Menggunakan Metode Rapid Aplication Development (RAD), Jurnal Rekayasa Dan Manajemen Sistem Informasi, Vol 1 No. 2, Agustus 2015, pp.23-30.

[3] Astuti.J.M. Irene (2014), Buku Pendamping Tematik Terpadu IPA Jilid 5, Jakarta: Erlangga.

[4] Genymobile.com. Genymotion. (diakses pada tanggal 05 Mei 2017) https://www.genymotion.com/

[5] H. Safaat Nazaruddin (2015), Pemrograman Aplikasi Mobile Smartphone dan Tablet PC Berbasis Android, Bandung: Informatika

[6] Kadir Abdul (2013), Zero A to A Pro Pemrograman Aplikasi Android, Yogyakarta: CV. ANDI Yogyakarta.

[7] Kirnanoro H. \& Maryana Ns. (2016), ANATOMI FISIOLOGI, Yogyakarta: Pustaka Baru Press

[8] Kosasi Sandi \& Yuliani Eka Ayu Dewi I, 2015, Penerapan Rapid Application Development Pada Sistem Penjualan Sepeda Online, Jurnal Simetris, Vol. 6 No. 1, April 2015 ISSN :2252-4983

[9] M.M. Rusdiana .H.A.Dr \& M.Kom. S.T., Irfan Moch. (2014), Sistem Informasi Manajemen, Bandung: Pustaka setia

[10] Oracle.com.Technetwork Java. (diakses paad tanggal 20 April 2017). http://www.oracle.com/technetwork/java/jav ase/downloads/jdk8-downloads-

2133151.html
[11] Putria Eka Narti. (2016), Pengantar Informasi Teknologi, Jakarta: Baduose Media

[12] Pembina Karya Penyusun Tim (2011), Anatomi Manusia: Bagaimana Tubuh Kita Bekerja, Surabaya: Karya Bina Swajaya

[13] Piyaneo (2014) . Rapid Application Development (RAD) . (Diakses pada tanggal 20 juli 2017). https://piyaneo.wordpress.com/2014/05/10/ rapid-application-development-rad/

[14] Sutabri Tata (2015), Sistem Informasi Manajemen, Yogyakarta: Andi.

[15] Salahuddin .M \& S.A Rosa (2016), Rekayasa Perangkat Lunak (Terstruktur dan Berorientasi Objek), Bandung: Informatika.

[16] Wati Rima Ega (2016), RAGAM MEDIA PEMBELAJARAN: Kata Pena. 